\title{
Aislamiento e identificación fenotípica y genotípica de cepas de Malassezia spp. en pacientes con pitiriasis versicolor
}

\author{
(Isolation and identification phenotypic and genotypic strains of \\ Malassezia spp. in patients with pytiriasis versicolor)
}

Carolina Espinoza Robles ${ }^{1 *}$, Pedro Brevis Azócar ${ }^{1}$

1. Departamento de Microbiología, Universidad de Talca, Chile

*Autor para correspondencia: carespinoza@utalca.cl

RECIBIDO: 24 de Octubre de 2017

APROBADO: 04 de Diciembre de 2017

DOI: 10.22370/bolmicol.2017.32.2.996

LOS AUTORES DECLARAN NO TENER CONFLICTO DE INTERESES

Palabras claves: Malassezia, Pitiriasis versicolor. Key words: Malassezia, Pytiriasis versicolor.

\section{RESUMEN}

Antecedentes: Pitiriasis versicolor (PV) es una infección micótica superficial crónica de la piel, debido a la colonización del estrato córneo por Malassezia sp. Tradicionalmente M. furfur era considerada el agente causal de PV, hoy en día se ha demostrado que las especies de Malassezia más comunes cultivadas a partir de de lesiones de PV son $M$. globosa y M. sympodialis.

Objetivos: Evaluar la epidemiología de la dermatomicosis PV, en pacientes de la ciudad de Talca, Chile.

Metodología: En este estudio, 19 pacientes diagnosticados con PV fueron evaluados. Se realizó identificación fenotípica e identificación molecular por técnica de PCR-RFLP. Para esto, se diseñaron partidores que amplificaron una zona del $26 \mathrm{~S}$ ADNr presente en todas las especies de Malassezia. Resultados: De un total de 19 pacientes con PV, 7 correspondieron a sexo masculino $(36,8 \%)$ y 12 a sexo femenino $(63,2 \%)$. Se obtuvieron 18 cepas, a partir de las pruebas fenotípicas fue posible identificar presuntivamente 11 especies de M. globosa $(61,1 \%)$ y 7 especies de $M$. sympodialis $(38,9 \%)$. Con los resultados obtenidos en la PCR-RFLP fue posible identificar 11 especies de M. globosa $(61,1 \%)$ y 7 especies $(38,9 \%)$ de $M$. sympodialis.

Conclusiones: La especie identificada fenotípicamente y molecularmente en mayor proporción fue Malassezia globosa seguida de Malassezia sympodialis. Por lo que hay concordancia entre ambas técnicas de identificación. Este es el primer trabajo de investigación realizado en Talca, Chile, que identificó las especies de Malassezia spp. involucradas en PV, siendo un aporte al estudio de este cuadro clínico.

\section{ABSTRACT}

Background: Pytiriasis versicolor (PV) is a fungal infection of the skin due to the stratum corneum colonization by Malassezia sp. M. furfur traditionally was considered the etiological agent of PV 
Aislamiento e identificación fenotípica y genotípica de cepas de Malassezia spp. - Espinoza C. et al.

but today it has been shown that M. globosa and M. sympodialis are the most common Malassezia species cultivated from PV lesions.

Objective: To evaluate the epidemiological features of PV in patient of the Talca city, Chile.

Method: In this study, 19 patients with diagnosis of PV were evaluated. Phenotypic and molecular identified were performed using PCR-RFLP. To do this, primers to amplify $26 \mathrm{~S}$ ADNr secuence were designed.

Result: From a total of 19 patients who presented PV, 7 were male $(36.8 \%)$ and 12 female patients $(63.2 \%)$. Eighteen strains were obtained, from the phenotypic tests, it was possible to presumably identify 11 species of $M$. globosa $(61.1 \%)$ and 7 species of $M$. sympodialis (38.9\%). With PCRRFLP results it was possible to identify 11 species of $M$. globosa (61.1\%) and 7 species (38.9\%) of $M$. sympodialis.

Conclusion: The most commonly isolated species were Malassezia globosa followed by Malassezia sympodialis. So, there is agreement between both techniques of identification. This is the first research work carried out in Talca, Chile, which identified the species of Malassezia spp. Involved in PV, being a contribution to the clinical diagnosis.

\section{INTRODUCCIÓN}

Las especies del género Malassezia son levaduras lipofílicas comúnmente comensales de la piel de humanos y animales de sangre caliente, que se encuentran asociadas con ciertas patologías debido a factores predisponentes. La colonización de estas levaduras parece estar influenciada por factores raciales, sexuales y cambios estacionales, con una frecuencia mayor en épocas cálidas y húmedas, pudiendo causar bajo ciertas condiciones infecciones superficiales a la piel. ${ }^{1}$ Entre las patologías provocadas por las especies de Malassezia se encuentran pitiriasis versicolor, dermatitis seborreica, foliculitis, dermatitis atópica, psoriasis e infecciones sistémicas, siendo esta última la que se asocia con sepsis por catéteres, fungemias e infecciones pulmonares en neonatos. ${ }^{2,3}$

Los primeros reportes de Malassezia fueron en 1846 por Eichstedt y en 1853 por Robin, quienes reconocieron la naturaleza fúngica de pitiriasis versicolor (PV) describiendo la presencia de elementos levaduriformes y filamentosos en raspados de piel de un paciente con afección de PV. Sin embargo, el género Malassezia fue creado el año 1889 por Baillon en honor a Malassez, quien en 1874 había informado sobre células brotantes de varias formas en el estrato córneo de pacientes con diversas enfermedades a la piel., ${ }^{5,6}$ Actualmente, Malassezia se clasifica taxonómicamente en reino Fungi, división Basidiomycota, clase Hymenomycetes, orden Tremellales, familia Filobasidium uniguttulatum. ${ }^{7} \mathrm{El}$ género comprende 14 especies. La revisión de 1996 del género dio lugar a siete especies aceptadas: M. furfur, M. pachydermatis, M. sympodialis, $M$. globosa M. obtusa, M. restricta y M. slooffiae. En la última década, siete nuevas especies, aisladas de humanos sanos y lesionados, y de piel animal, han sido aceptadas: $M$. dermatis, M. japonica, M. yamatoensis, M. nana, M. caprae, M. equina y M. cuniculi. ${ }^{8}$

Las células del género Malassezia, pueden presentar forma globosa a subglobosa, ovales o cilíndricas, dependiendo de la especie. Malassezia pachydermatis es ovalada con forma de maní y mide aproximadamente 2-3 $\mu \mathrm{m}$ de ancho y 4-5 $\mu \mathrm{m}$ de longitud. Las otras especies pueden diferir ligeramente de esta especie en forma y tamaño. ${ }^{9}$

El desconocimiento de las verdaderas necesidades nutricionales, y por consecuencia los problemas al cultivar estas especies, han permitido dilucidar la fisiología de estas levaduras. Se ha comprobado que las especies del género Malassezia no fermentan azúcares, son lipofílicas, debi- 
do a que no son capaces de sintetizar ácidos grasos saturados de C12-C16, lo que se manifiesta en una fuente exógena de ácidos grasos para su desarrollo, a excepción de $M$. pachydermatis siendo la única especie de este género que no necesita sustancias lipídicas para desarrollarse. ${ }^{5}$

Comúnmente las especies de Malassezia se pueden encontrar en la piel de personas sanas, sin embargo estos organismos también han sido asociados a una amplia gama de enfermedades cutáneas y sistémicas, siendo la patología más frecuente la pitiriasis versicolor. En animales las patologías causadas por Malassezia spp. también han sido de gran interés. Es por esta razón que el papel patogénico de Malassezia spp. en las patologías que causa es un tema de investigación tanto en medicina humana como veterinaria.

La pitiriasis versicolor (PV) es una infección micótica superficial crónica de la piel. Se caracteriza por máculas hipocrómicas o hipercrómicas levemente descamativas, estos cambios pigmentarios son debido a la colonización del estrato córneo por Malassezia sp. Generalmente, las lesiones pueden tomar forma de máculas redondas $\mathrm{u}$ ovaladas o pápulas, aunque en casos avanzados las lesiones pueden volverse confluente. Estas lesiones se localizan comúnmente en la parte superior del tronco, así como en la parte superior de brazos, en cuello y cara. Algunos pacientes experimentan prurito leve, sin embargo, PV es generalmente asintomática y la mayoría de los pacientes principalmente se quejan de la apariencia estética de la enfermedad. ${ }^{10,11,12}$

Tradicionalmente $M$. furfur era considerada el agente causal de PV, hoy en día se ha demostrado que las especies de Malassezia más comunes cultivadas a partir de de lesiones de PV son M. globosa y M. sympodialis, seguidas por M. slooffiae, $M$. restricta y $M$. furfur, las cuales pueden aislarse asociadas o solas. ${ }^{2,13,14}$

\section{MATERIALES Y MÉTODOS}

Pacientes: Un total de 19 pacientes diagnosticados con PV fueron evaluados. Todos provenientes de la ciudad de Talca. Las normas del Comité de Ética Humana se cumplieron mediante el consentimiento informado. (ver anexo)

Recolección y cultivo de muestras: Se obtuvieron escamas de piel raspando las lesiones con bisturí y cinta adhesiva trasparente. Se realizó examen micológico directo con hidróxido de potasio $(\mathrm{KOH})$ al 10\% y azul de lactofenol. Las escamas recolectadas fueron inoculadas en Agar Dixon modificado (mDA) e incubadas a $32^{\circ} \mathrm{C}$ durante 2 semanas. 11

Identificación fenotípica: Se llevó a cabo el protocolo descrito por Guého-Kellerman E. et al. A las colonias obtenidas se les realizó prueba de catalasa, prueba de desdoblamiento de la esculina y prueba de asimilación de Tween 20, 60, 40, 80 (Merck) y Cremophor EL (Calbiochem). 15

\section{Identificación molecular por técnica de PCR-} RFLP: A los cultivos obtenidos previamente en la identificación fenotípica, se les realizó extracción del ADN de Malassezia spp. y PCR-RFLP siguiendo el protocolo descrito por Sosa M. y Giusiano G.16 Los partidores utilizados amplificaron una zona del 26S ADNr presente en todas las especies de Malassezia (Mala 1 y Mala 2).

- Mala1: 5' -TAACAAGGATTCCCCTAGTA-3' - Mala2: 5' -ATTACGCCAGCATCCTAAG-3'

Los amplicones se sometieron a una primera restricción enzimática con la enzima CfoI (Promega). Cada vez que se observó un patrón de restricción compatible con Malassezia sympodialis o Malassezia dermatis, se realizó una segunda restricción enzimática con MboI (Fermentas), según los protocolos del proveedor. Para el análisis de los perfiles de restricción, se utilizaron las siguientes 
cepas de referencia, CBS 7707 Malassezia globosa, CBS 7019 Malassezia furfur y CBS 7222 Malassezia sympodialis.

\section{RESULTADOS}

De los 19 pacientes diagnosticados con PV, 7 correspondieron a sexo masculino $(36,8 \%)$ y 12 a sexo femenino $(63,2)$. Con respecto a la ubicación anatómica de las lesiones, 8 pacientes presentaron máculas en espalda $(42,1 \%), 2$ en pecho $(10,5 \%), 4$ en hombros $(21,1 \%), 1$ en el costal derecho $(5,3 \%), 2$ en espalda y pecho $(10,5 \%)$ y 2 en abdomen y pecho $(10,5 \%)$ (Tabla $\left.\mathrm{N}^{\circ} 1\right)$. Es necesario considerar que del total de los casos espalda (sola o asociado a otro lugar anatómico) y pecho (solo o asociado a otro lugar anatómico) fueron los más frecuentes con un $52,6 \%$ y un $31,6 \%$ respectivamente. (Tabla $\mathrm{N}^{\circ} 2$ ). En relación a la pigmentación de las máculas, 11 pacientes presentaron máculas hipocrómicas $(57,9 \%)$ y 8 pacientes máculas hipercrómicas $(42,1 \%)$.

Tabla 1. Frecuencia y porcentajes de los distintos lugares anatómicos solos y asociados en que se ubicaban las máculas de pacientes con pitiriasis versicolor.

\begin{tabular}{|l|l|r|r|}
\hline \multicolumn{2}{|c|}{} & Frecuencia & Porcentaje \\
\hline \multirow{4}{*}{ Válidos } & 8 & 42,1 \\
\cline { 2 - 4 } & Espalda & 2 & 10,5 \\
\cline { 2 - 4 } & Pecho & 4 & 21,1 \\
\cline { 2 - 4 } & Hombro & 1 & 5,3 \\
\cline { 2 - 4 } & Costal derecho & 2 & 10,5 \\
\cline { 2 - 4 } & Espalda y Pecho & 2 & 10,5 \\
\cline { 2 - 4 } & Abdomen y Pecho & 19 & 100,0 \\
\cline { 2 - 4 } & Total & & \\
\hline
\end{tabular}

Tabla 2. Frecuencia y Porcentajes de los distintos lugares anatómicos que por si solo presentan máculas de pacientes con pitiriasis versicolor.

\begin{tabular}{|l|c|c|c|}
\hline \multicolumn{2}{|c|}{} & \multicolumn{2}{c|}{ Resultado } \\
\cline { 3 - 4 } \multicolumn{1}{|c|}{} & $N^{\circ}$ & Porcentaje \\
\hline \multirow{4}{*}{ Lugar Anatómico } & Espalda & 10 & $52,6 \%$ \\
\cline { 2 - 4 } & Pecho & 6 & $31,6 \%$ \\
\cline { 2 - 4 } & Abdomen & 2 & $10,5 \%$ \\
\cline { 2 - 4 } & Hombro(s) & 4 & $21,1 \%$ \\
\cline { 2 - 4 } & Cuello & 1 & $5,3 \%$ \\
\cline { 2 - 4 } & Costal derecho mama & 1 & $5,3 \%$ \\
\hline \multirow{2}{*}{ Total } & 24 & $100,0 \%$ \\
\hline
\end{tabular}

Examen micológico directo: Se examinaron 20 muestras, 2 obtenidas de un mismo paciente (pecho y espalda). A 18 de ellas se les observó racimos de levaduras redondas en gemación e hifas cortas septadas lo que sugirió la presencia de Malassezia spp. y en 2 muestras no se observaron elementos micóticos. (Fig. $\mathrm{N}^{\circ} 1$ )

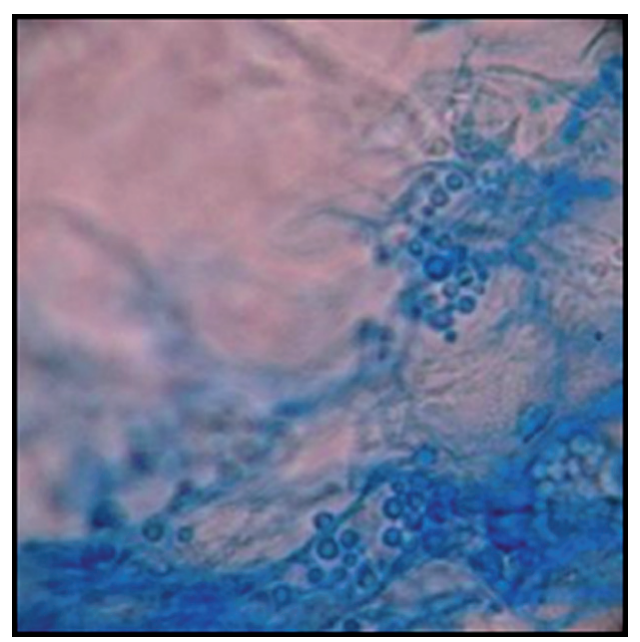

Figura 1. Levaduras e hifas septadas en examen micológico directo, "espaguetis y albóndigas". (Tinción azul de lactofenol) 
Aislamiento e identificación fenotípica y genotípica de cepas de Malassezia spp. - Espinoza C. et al.

Identificación a partir de escamas de piel: Se obtuvieron 18 cultivos positivos, a los cuales se les realizó identificación fenotípica y molecular por técnica de PCR-RFLP.

Analisis fenotípico: En la prueba de la catalasa, la producción de burbujas de gas indicó una reacción positiva, causada por la liberación de oxígeno libre. En la prueba de la bilis esculina, el viraje a color negro del medio representó una prueba positiva, la ausencia de ennegrecimiento del medio indica la falta de actividad de la $\beta$ - glucosidasa. En la prueba de asimilación de Tween 20, 40, 60 y 80 y Cremophor EL, la lectura positiva correspondió a la formación de un halo de opacidad alrededor de los diferentes Tween y Cremophor EL. Con los resultados de las pruebas fenotípicas fue posible identificar presuntivamente 11 especies de $M$. globosa $(61,1 \%)$ y 7 especies de $M$. sympodialis $(38,9 \%)$.

En la Tabla $\mathrm{N}^{\mathrm{o}} 3$ se resume los resultados de la identificación fenotípica realizada a los 19 pacientes con PV, donde M: Masculino, F: Femenino, P: Positivo, N: Negativo y $+/-$ : Poco crecimiento.

Tabla 3. Resumen de la identificación fenotípica a los 19 pacientes estudiados con pitiriasis versicolor. (M: Masculino, F: Femenino, P: Positivo, N: Negativo y +/- : Poco crecimiento)

\begin{tabular}{|c|c|c|c|c|c|c|c|c|c|c|c|c|c|c|}
\hline $\begin{array}{c}\mathrm{N} N= \\
\text { muestra }\end{array}$ & Edad & Sexo & $\begin{array}{l}\text { Ubicación } \\
\text { Anatómica }\end{array}$ & Tratto. & $\begin{array}{l}\text { Examen } \\
\text { Directo }\end{array}$ & $\begin{array}{l}\text { Cultivo } \\
\text { Dixon } \\
\text { modif. }\end{array}$ & Catalasa & $\begin{array}{l}\text { Bilis } \\
\text { Esculina }\end{array}$ & $\begin{array}{l}\text { Tween } \\
20\end{array}$ & $\begin{array}{l}\text { Tween } \\
40\end{array}$ & $\begin{array}{l}\text { Tween } \\
60\end{array}$ & $\begin{array}{c}\text { Tween } \\
80\end{array}$ & CrEL & Especie \\
\hline 1 & 13 & M & Espalda & No & $P$ & $\mathrm{P}$ & $P$ & $\mathrm{~N}$ & $+/-$ & $P$ & $P$ & $\mathrm{~N}$ & $\mathrm{~N}$ & M. globosa \\
\hline 2 & 40 & M & Hombro & No & $P$ & $P$ & $P$ & $\mathrm{~N}$ & $+/-$ & $P$ & $P$ & $\mathrm{~N}$ & $\mathrm{~N}$ & M. globosa \\
\hline 3 & 40 & $\mathrm{~F}$ & $\begin{array}{l}\text { Espalda y } \\
\text { Pecho }\end{array}$ & No & $P$ & $\mathrm{P}$ & $P$ & $P$ & $\mathrm{P}$ & $P$ & $P$ & $P$ & $\mathrm{~N}$ & M. sympodialis \\
\hline 4 & 26 & F & Espalda & No & $P$ & $P$ & $P$ & $\mathrm{~N}$ & $\mathrm{~N}$ & $P$ & $P$ & $\mathrm{~N}$ & $\mathrm{~N}$ & M. globosa \\
\hline 5 & 32 & F & Pecho & No & $P$ & $\mathrm{~N}$ & - & - & - & - & - & - & - & - \\
\hline 6 & 22 & $\mathrm{~F}$ & $\begin{array}{l}\text { Abdomen } \\
\text { Pecho }\end{array}$ & No & $P$ & $P$ & $P$ & $\mathrm{~N}$ & $+/$ & $P$ & $P$ & $\mathrm{~N}$ & $\mathrm{~N}$ & M. globosa \\
\hline 7 & 59 & M & Espalda & No & $P$ & $P$ & $P$ & $\mathrm{~N}$ & $+/-$ & $P$ & $P$ & $\mathrm{~N}$ & $\mathrm{~N}$ & M. globosa \\
\hline 8 & 41 & F & Pecho & No & $P$ & $P$ & $P$ & $\mathrm{~N}$ & $+/-$ & $P$ & $P$ & $\mathrm{~N}$ & $\mathrm{~N}$ & M. globosa \\
\hline 9 & 22 & F & $\begin{array}{l}\text { Abdomen } \\
\text { Pecho }\end{array}$ & No & $P$ & $\mathrm{P}$ & $P$ & $\mathrm{~N}$ & + & $\mathrm{P}$ & $\mathrm{P}$ & $\mathrm{N}$ & $\mathrm{N}$ & M. globosa \\
\hline 10 & 47 & $F$ & Espalda & No & $P$ & $P$ & $P$ & $P$ & $P$ & $P$ & $P$ & $P$ & $+/-$ & M. sympodialis \\
\hline 11 & 42 & M & Espalda & NO & $P$ & $P$ & $P$ & $P$ & $P$ & $P$ & $P$ & $P$ & $+/-$ & M. sympodialis \\
\hline 12 & 17 & $\mathrm{~F}$ & Hombro & No & $P$ & $P$ & $P$ & $P$ & $P$ & $P$ & $P$ & $P$ & $+/$. & M. sympodialis \\
\hline 13 & 15 & $\mathrm{~F}$ & Espalda & SI & $\mathrm{N}$ & $\mathrm{N}$ & - & - & - & - & - & - & - & - \\
\hline 14 & 51 & $\mathrm{~F}$ & $\begin{array}{l}\text { Costal } \\
\text { derecho }\end{array}$ & No & $P$ & $P$ & $P$ & $\mathrm{~N}$ & $+/-$ & $P$ & $P$ & $\mathrm{~N}$ & $\mathrm{~N}$ & M. globosa \\
\hline 15 & 18 & $\mathrm{~F}$ & Hombro & No & $P$ & $P$ & $P$ & $\mathrm{~N}$ & $\mathrm{~N}$ & $P$ & $P$ & $\mathrm{~N}$ & $\mathrm{~N}$ & M. globosa \\
\hline $\begin{array}{l}16 \mathrm{a} \\
16 \mathrm{~b} \\
\end{array}$ & 18 & F & $\begin{array}{l}\text { Pecho } \\
\text { Espalda }\end{array}$ & No & $\begin{array}{l}\mathrm{P} \\
\mathrm{P}\end{array}$ & $\begin{array}{l}\mathrm{P} \\
\mathrm{P}\end{array}$ & $\begin{array}{l}\mathrm{P} \\
\mathrm{P}\end{array}$ & $\begin{array}{l}\mathrm{P} \\
\mathrm{N} \\
\end{array}$ & $\begin{array}{c}\mathrm{P} \\
+/-\end{array}$ & $\begin{array}{l}\mathrm{P} \\
\mathrm{P}\end{array}$ & $\begin{array}{l}\mathrm{P} \\
\mathrm{P}\end{array}$ & $\begin{array}{l}\mathrm{P} \\
\mathrm{N} \\
\end{array}$ & + & $\begin{array}{l}\text { M. sympodialis } \\
\text { M. globosa }\end{array}$ \\
\hline 17 & 20 & M & Hombro & No & $\mathrm{N}$ & $\mathrm{P}$ & $P$ & $P$ & $P$ & $P$ & $P$ & $P$ & $\mathrm{~N}$ & M. sympodialis \\
\hline 18 & 20 & M & Espalda & No & $P$ & $P$ & $P$ & $P$ & $P$ & $P$ & $P$ & $P$ & $\mathrm{~N}$ & M. sympodialis \\
\hline 19 & 16 & M & Espalda & No & $P$ & $P$ & $P$ & $\mathrm{~N}$ & $+/$. & $P$ & $P$ & $\mathrm{~N}$ & $\mathrm{~N}$ & M. globosa \\
\hline
\end{tabular}




\section{Identificación molecular por técnica de PCR-}

RFLP: Las 18 muestras analizadas amplificaron un producto de PCR de aproximadamente $580 \mathrm{pb}$. (Fig. $\mathrm{N}^{\circ} 2$ ) En la restricción enzimática con $\mathrm{CfoI}$ se obtuvo diferentes patrones de bandas, 11 muestras presentan un primer fragmento de aproximadamente $500 \mathrm{pb}$ y un segundo fragmento con aproximadamente $100 \mathrm{pb}$ correspondiente a Malassezia globosa. (Fig.N³) Siete muestras presentaron un primer fragmento entre las 300 y $400 \mathrm{pb}$ y un segundo fragmento de aproximadamente $200 \mathrm{pb}$ correspondiente a Malassezia sympodialis o $\mathrm{Ma}$ lassezia dermatis, por lo que fue necesario realizar una segunda restricción enzimática con MboI, en la que se obtuvo un patrón de banda menor a 500 $\mathrm{pb}$ en las 7 muestras analizadas, correspondiendo a Malassezia sympodialis. (Fig. $\mathrm{N}^{\mathrm{0}} 4$ ).

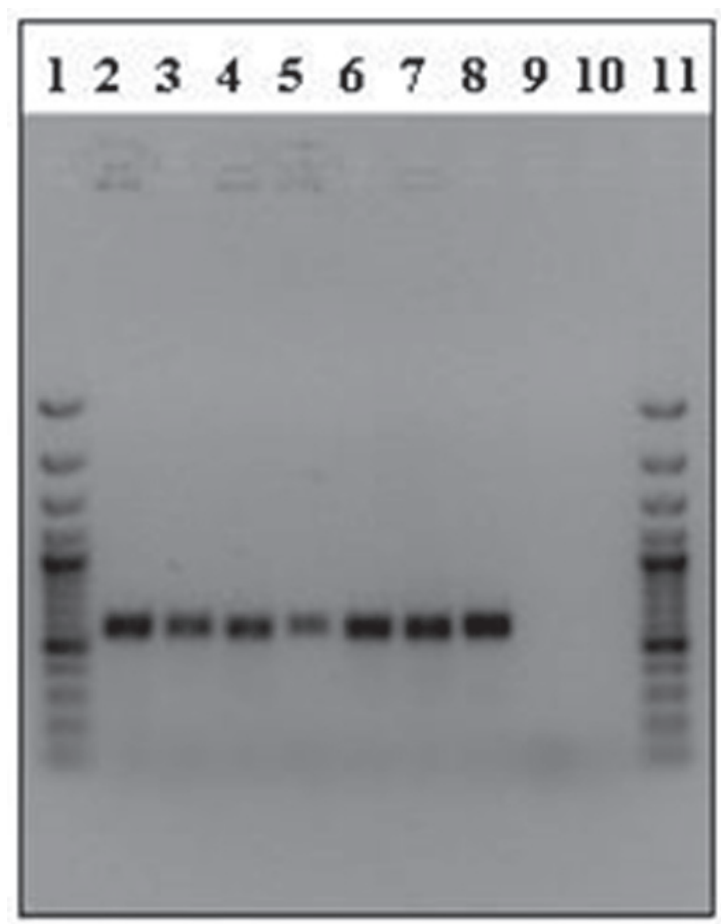

Figura 2. Producto de PCR de cepas de Malassezia spp. aisladas a partir de cultivo de escamas de piel. 1) y 11) Marcador de PM 100 pb, 2) a 8) Amplicón de $580 \mathrm{pb}$ aprox. correspondientes a Malassezia sp.; 9) Control Negativo.

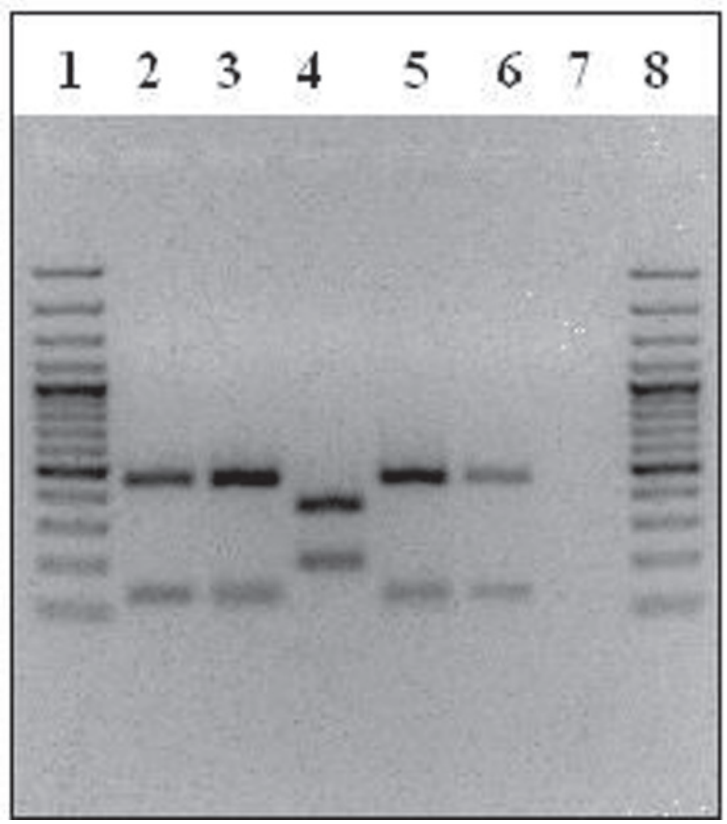

Figura 3. Producto de Restricción Enzimática con Cfol cepas de Malassezia spp. aisladas a partir de cultivos de escamas de piel. 1) y 8) Marcador de PM 100 pb, 2) Muestra $\mathrm{N}^{\circ} 1$ : M. globosa, 3) Muestra $\mathrm{N}^{\circ}$ 2: . globosa, 4) Muestra $\mathrm{N}^{\circ}$ 3: Malassezia sp., 5) Muestra $\mathrm{N}^{\circ}$ 4: M. globosa, 6) Muestra $\mathrm{N}^{\circ}$ 6: M. globosa. 7) Control Negativo.

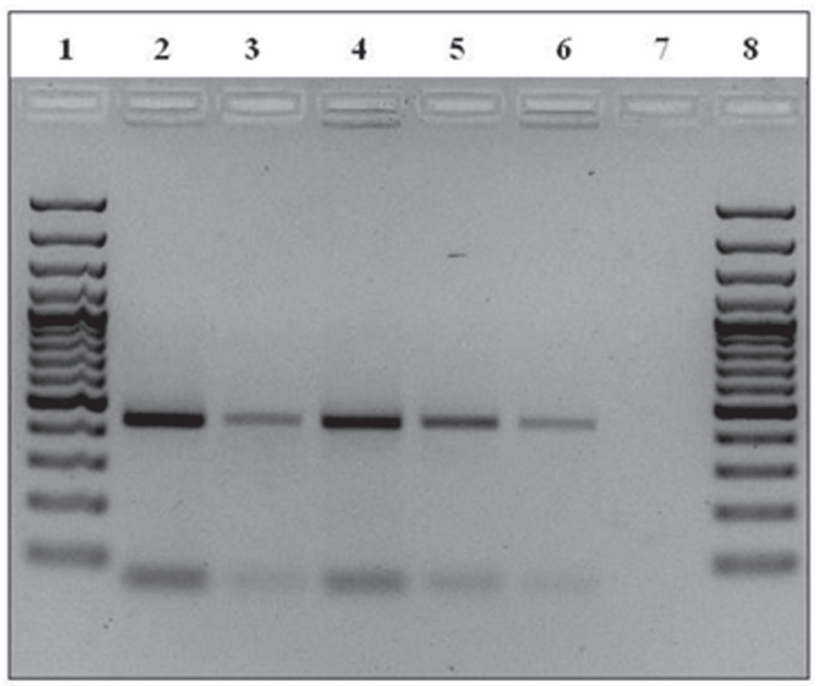

Figura 4. Producto de Restricción Enzimática con MboI de cepas de Malassezia spp. aisladas a partir de cultivos de escamas de piel. 1) y 8) Marcador de PM 100 pb, 2) a 6) Muestras correspondientes a $M$. sympodialis. 7) Control Negativo. 
Con los resultados obtenidos en la PCRRFLP fue posible identificar 11 especies de $M$. globosa $(61,1 \%)$ y 7 especies $(38,9 \%)$ de M. sympodialis. (Tabla $\mathrm{N}^{\circ} 4$ )

Tabla 4. Frecuencia y porcentaje de las especies de Malassezia identificada con PCR-RFLP.

\begin{tabular}{|c|c|c|c|}
\hline & & \multicolumn{2}{|c|}{ Resultados } \\
\hline & & $\mathrm{N}^{\circ}$ & Porcentaje \\
\hline \multirow{2}{*}{ Especie } & M. globosa & 11 & $61,1 \%$ \\
\hline & M. sympodialis & 7 & $38,9 \%$ \\
\hline \multicolumn{2}{|l|}{ Total } & 18 & $100,0 \%$ \\
\hline
\end{tabular}

\section{DISCUSIÓN}

Pitiriasis versicolor es una micosis superficial frecuente en climas tropicales y templados. En Chile es una dermatomicosis que tiene escasos estudios publicados, pero por las condiciones climáticas que presenta nuestro país se sabe que es más frecuente en épocas de verano, debido a que el clima es caluroso y húmedo. Sin embargo, las especies asociadas en mayor proporción se desconocen. En el año 2003 Rendic E. y colaboradores caracterizaron las especies de Malassezia spp. en un total de 160 chilenos, de los cuales a un 76,5\% de pacientes con Dermatitis seborreica (DS) y a un $82 \%$ de un grupo control, se les encontró presencia de Malassezia sp., logrando identificar la especie involucrada en 50 levaduras aisladas, correspondientes a: 36 M. globosa (72\%), 7 M. sympodialis (14\%), 5 M. furfur (10\%) y 2 M. slooffiae (4\%). ${ }^{16}$ En el año 2010 Cruz R. y colaboradores reportaron un Caso Clínico poco frecuente de PV por $M$. pachydermatis en una paciente de 11 años de edad, de nacionalidad francesa residente en Chile y dueña de un gato. La identificación de la especie se realizó mediante morfofisiología y biología molecular. ${ }^{17}$
El aislamiento, identificación y mantenimiento de las especies del género Malassezia es complejo debido a su variabilidad morfológica, su capacidad de presentar forma micelial y de levadura simultáneamente, y a sus requerimientos estrictos de crecimiento. La identificación sólo a partir de sus características fenotípicas ya no es suficiente, hoy en día es necesario recurrir a métodos moleculares que sean certeros, reproducibles y de bajo costo que permitan dilucidar el genotipo de todas las especies de Malassezia, su epidemiología y patogénesis. ${ }^{5}$

Se realizó el protocolo descrito por Sosa y Giusiano, el cual se basa en una modificación de la técnica de PCR-RFLP descrita por Mirhendi y col., dicha modificación confiere una mayor practicidad a la técnica y disminuye los costos de la misma. ${ }^{18}$

El rol del sexo en la propensión a desarrollar PV, no está bien definida. En este estudio la incidencia de PV fue mayor en mujeres, lo que puede deberse a la mayor preocupación estética de la mujer en comparación con el hombre, lo que las lleva a consultar al médico dermatólogo.

Con respecto a los lugares anatómicos que con mayor frecuencia presentan lesiones de PV, el 2004 en Iran describieron que la espalda presentó un $22 \%$ de lesiones, el cuello un $21 \%$ y el pecho un $17 \%$, de los 75 casos estudiados. ${ }^{19}$ En Bolivia reportaron que la ubicación de las lesiones fue mayoritariamente en brazos y antebrazos con un $36,11 \%$, en la cara con un $25 \%$ y con menor frecuencia en cara ventral de tórax un $10,65 \%$, en piernas un $9,72 \%$ y en dorso de tórax y cuello un 9,26\%.20 En el presente estudio, los lugares anatómicos que con frecuencia presentaron lesiones de PV fueron espalda y pecho con un $52,6 \%$ y un $31,6 \%$ respectivamente. 
En Brasil se describió que las máculas más frecuentes fueron hipocrómicas con un 94,11\%, las máculas hipercrómicas sólo representaron un 0,98\% y también reportó una asociación de máculas hipocrómicas e hipercrómicas en un $0,98 \% .21$ En nuestro estudio se analizaron un total de 20 lesiones de PV, de las cuales 11 fueron máculas hipocrómicas $(57,9 \%)$ y 8 máculas hipercrómicas $(42,1 \%)$.

Se han hecho múltiples estudios sobre la especie de Malassezia involucrada en PV a nivel mundial, entre los cuales se ha descrito que las especies involucradas con mayor frecuencia han sido M. globosa, M. sympodialis y M. furfur.

En España el año 1999, se aisló una sola especie en 51 pacientes, correspondientes a $M$. globosa (52\%), M. sympodialis $(13,3 \%)$ y M. restricta $(2,7 \%)$, y a su vez fue posible aislar dos especies asociadas en 24 pacientes, correspondientes a $M$. globosa con $M$. sympodialis $(25,3 \%)$ y M. globosa con M.slooffiae (6,7\%). M. globosa fue encontrada como única especie de Malassezia en lesiones de PV en la mitad de las ocasiones (52\%). La asociación más habitual de esta especie fue con $M$. sympodialis, y en mucha menor medida con $M$. slooffiae. Del total de los casos, la especie predominante fue $M$. globosa, que se aisló sola o asociada en el $84 \%$ de los casos, seguida por M. sympodialis que se encontró sola o asociada en el 38,6\% de los casos. ${ }^{22}$ En Iran el año 2004, a partir de 94 pacientes con PV, se aisló con mayor frecuencia a M. globosa (53.3\%), seguido de M. furfur $(25,3 \%)$, M. sympodialis $(9,3 \%), M$. obtusa $(8,1 \%)$ y $M$. slooffiae (4.0\%). Luego en el 2010, en el mismo país, con un total de 116 pacientes que presentaron cultivos positivos para Malassezia spp. se aisló a $M$. globosa $(31,3 \%), M$. furfur $(20,5 \%), M$. pachydermatis $(7,2 \%), M$. restricta $(7,2 \%)$ y $M$. slooffiae $(3,6 \%) .19,23$

Sin embargo en Argentina, se identificó las especies de Malassezia involucradas en 264 pa- cientes con PV, donde $M$. sympodialis (51\%) fue la especie más aislada, seguida por $M$. globosa (40\%), M. furfur (7\%), M. obtusa (1\%) y M. slooffiae (1\%).24 En Bolivia, analizaron 216 muestras de pacientes con $\mathrm{PV}$, de los cuales se identificó a M. sympodialis en un 40,22\%, M. globosa $29,0 \%$, M.furfur y $M$. obtusa $5,59 \%, M$. restricta y $M$. slooffiae 2,23\%. 20 En Brasil, se describió que la especie aislada con mayor frecuencia fue $M$. sympodialis con $16,66 \%$, M. furfur con un $12,50 \%$, M. globosa con un $11,45 \%$ y $M$. slooffiae con un $2,10 \% .25$

En el presente estudio realizado en Talca, Chile, se identificó tanto fenotípica como molecularmente, a M. globosa con un $61,1 \%$ de frecuencia y a $M$. sympodialis con un $38,9 \%$ de frecuencia. Coincidiendo con las especies más aisladas en los estudios realizados en España e Iran.

En la identificación fenotípica, las pruebas de bioquímica arrojaron resultados que concordaron con la especie a identificar. En la identificación molecular por PCR-RFLP de igual manera, fue posible obtener un perfil de bandas único y característico de la especie. Sin embargo, es necesario destacar que la identificación fenotípica presenta inconvenientes en la lectura que puede fallar por los requerimientos nutricionales especiales de éstas levaduras lipofílicas, por lo que los métodos moleculares han ayudado a resolver dichos inconvenientes.

\section{CONCLUSIONES}

- La especie identificada fenotípicamente y molecularmente en mayor proporción fue Malassezia globosa seguida de Malassezia sympodialis.

- Los lugares anatómicos que presentaron lesiones de PV más frecuentes fueron espalda (sola o asociado a otro lugar anatómico) y pecho (solo o asociado a otro lugar anatómico) con un 52,6\% y un $31,6 \%$ respectivamente. 
- Tanto en la identificación fenotípica como en la identificación molecular las especies aisladas fueron Malassezia globosa y Malassezia sympodialis correspondientes a un $61,1 \%$ y un $38,9 \%$ respectivamente. Por lo que hay concordancia entre ambas técnicas de identificación.
- Este es el primer trabajo de investigación realizado en Talca, Chile, que identificó las especies de Malassezia spp. involucradas en Pitiriasis versicolor, siendo un aporte al estudio de este cuadro clínico.

\section{REFERENCIAS}

1. González E., Rodriguez S., Del Monte M., Briceño M., Sintjago S., Mesa L., et al. Aislamiento e identificación de especies del género Malassezia en piel sana de niños desnutridos y eutróficos de multihogares de cuidado diario. Invest. Clin. 2009; 50(2): $145-152$.

\section{Gupta A., Batra R., Bluhm R., Boekhout} Teun., Dawson T. Skin diseases associated with Malassezia species. J. Am. Acad. Dermatol. 2004; 51: 785-798.

3. Devos SA., van der Valk PG. The relevance of skin prick tests for Pityrosporum ovale in patients with head and neck dermatitis. Allergy. 2000; 55(11): 1056-1058.

4. Hernández F., Méndez L., Bazán E., Arevalo A., Valera A., López R. Especies de Malassezia asociadas a diversas dermatosis y a piel sana en población mexicana. Rev. Iberoam. Micol. 2003; 20: 141-144.

5. Giusiano G. Malassezia Estado del conocimiento y perspectivas en su estudio. Revista Argentina de Microbiología 2006; 38: 41-48.

6. Ashbee A., Evans E. Immunology of Diseases Associated with Malassezia Species. Clinical Microbiology Reviews 2002; 15(1): 21-57.

7. Faergemann J. Atopic Dermatitis and Fungi. Clinical Microbiology Reviews 2002; 15(4): 545-563.

8. Gaitanis G., Magiatis P., Hantschke M., Bassukas ID., Velegraki A., The Malassezia genus in skin and systemic diseases. Clin. Microbiol. Rev. 2012; 25(1): 106-41.

9. Chen T., Hill P. The biology of Malassezia organisms and their ability to induce immune responses and skin disease. Veterinary Dermatology 2005; 16: 4-26.

10. Gupta A., Bluhm R., Summerbell R. Pityriasis versicolor. European Academy of Dermatology and Venereology JEADV 2002; 16: 19-33

11. Padilla C., Rodríguez M., Medina D., Gutierrez S., Mendoza L., Ramos A. Pitiriasis versicolor. Presentación de tres casos. Rev. Cent. Dermatol Pascua 2004; 13(1): 49-55.

12. Sosa M., Giusiano G., Mangiaterra M., Bustillo S. Agentes etiológicos de pitiriasis versicolor. Universidad Nacional del Nordeste, Comunicaciones científicas tecnológicas 2005. Resumen:M-015. Argentina, 2005.

13. Padilla M. Pitiriasis versicolor. Dermatología Rev. Mex. 2005; 49(4): 157-167.

14. Crespo V., Ojeda A., Vera A., Crespo A., Sanchez F. Malassezia globosa as the causative agent of pityriasis versicolor. British Journal of Dermatology 2000; 143: 799-803.

15. Guého-Kellerman E., Boekhout T., Begerow D. Biodiversity, Phylogeny and Ultrastructure. Malassezia and the Skin 2010 ; 2: 17-63.

16. Rendic E., Díaz A., Fich F. Caracterización de 
especies del género Malassezia en pacientes con dermatitis seborreica y en controles. Rev. Med. Chile 2003; 131:1295-1300.

17. Cruz R., Vieille P., Giusiano G., Sosa M. Pitiriasis Versicolor por Malassezia pachydermatis: Caso Clínico. Boletín Micológico 2010; 25: 37-41.

18. Sosa M, Giusiano G. Caracterización molecular de Malassezia spp. mediante PCR-RFLP. En: Merino L, Giusiano G. (Eds.). Manual de Métodos Moleculares para estudios microbiológicos. Buenos Aires, Asoc. Argentina de Microbiología, 2011: 152-154.

19. Tarazooie B., Kordbacheh P., Zaini F., Zomorodian K., Saadat F., Zeraati H., et al. Study of the distribution of Malassezia species in patients with pityriasis versicolor and healthy individuals in Tehran, Iran. BMC Dermatol. 2004; 4:5.

20. Tango E., Vargas J. Caracterización fenotípica de las especies del género Malassezia aisladas de pacientes con pitiriasis versicolor en Santa Cruz-Bolivia. Rev. de enferm. Infecc. Trop. 2009; 1 (1): 33-36.
21. Framil V., Melhem M., Szeszs M., Corneta E., Zaitz C. Pitiríase versicolor: isolamento e identificačão das principais espécies de Malassezia. An Bras Dermatol. 2010; 85: (1): 111-114.

22. Crespo V., Ojeda A., Vera A., Crespo A., Sanchez F. Isolation and identification of Malassezia spp. In pytiriasis versicolor, seborrheic dermatitis and healthy skin. Rev Iberoam Micol. 1999; 16 (S):S16-21.

23. Rasi A., Naderi R., Behzadi A., Falahati M., Farehyar S., Honarbakhsh Y., et al. Malassezia yeast species isolated from Iranian patients with pityriasis versicolor in a prospective study. Mycoses. 2010; 53 (4): 350-355.

24. Ramadán S., Sortino M., Bulacio L., Marozzi M., López C., Ramos L. Prevalence of Malassezia species in patients with pityriasis versicolor in Rosario, Argentina. Rev Iberoam Micol. 2012; 29 (1): 14- 19.

25. Framil V., Melhem M., Szeszs M., Zaitz C. New aspects in the clinical course of pityriasis versicolor. An Bras Dermatol. 2011; 86: (6): 1135-1140. 


\section{ANEXO}

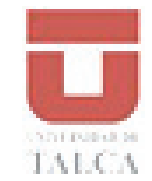

\section{CONSENTIMIENTO INFORMADO}

Título del Proyecto: Aislamiento e identificación de Malassezia spp. en pacientes con Pitiriasis versicolor y Dermatitis seborreica en la ciudad de Talca

\section{Sr. (Sra., Srta.):}

El propósito de este documento es entregarle toda la información necesaria para que Ud. pueda decidir libremente si desea participar en la investigación que se le ha explicado verbalmente, y que a continuación se describe en forma resumida:

\section{Resumen del proyecto:}

El presente proyecto será realizado en conjunto con el médico tratante quien diagnosticará al paciente y el profesional encargado de los procesos para la obtención de muestras clínicas, T.M Carolina Espinoza Robles.

Las micosis superficiales son infecciones causadas por hongos que afectan a tejidos como la piel, el cuero cabelludo y uñas.

Pitiriasis versicolor y dermatitis seborreica son micosis superficiales provocadas por hongos levaduriformes pertenecientes al género Malassezia.

En Chile existen muy pocos estudios y datos que puedan orientar sobre la epidemiología de dichas micosis. Es por esto que el objetivo del presente proyecto es determinar la especie o las especies del género Malassezia causantes de pitiriasis versicolor y dermatitis seborreica en pacientes de la ciudad de Talca.

Para cumplir dicho objetivo es necesario fotografiar y recolectar muestras de lesiones en pacientes que presenten la patología de interés, previamente diagnosticada por el médico tratante.

A continuación se detallan los procedimientos para la obtención de la muestra.

1. Fotografías de lesiones: Se obtendrán de las zonas anatómicas que presenten las lesiones, sin mostrar el rostro del paciente, para ser almacenadas como respaldo. Dicha información será guardada por el investigador T.M Carolina Espinoza Robles. 
2. Obtención de escamas con cinta adhesiva trasparente: Consiste en limpiar con alcohol al 70\% la zona afectada, adherir a la lesión una cinta trasparente (scotch) por un par de segundos y retirarla para posteriormente realizar un análisis microscópico. Los resultados serán entregados al médico tratante.

3. Raspado de la lesión: Este procedimiento permitirá obtener escamas de piel, las que serán recibidas en una placa de Petri estéril. Se raspará levemente con un porta objeto limpio todas las lesiones previamente limpiadas con alcohol al 70\%, sin causar daño, arrastrando sólo las escamas superficiales, hasta que se obtenga una cantidad de escamas suficientes para ser cultivadas. El porta objeto es una lamina de vidrio utilizada para observar muestras clínicas en el microscopio, por tanto el procedimiento no es invasivo.

Una vez obtenida la muestra clínica será analizada en el Laboratorio de Micología del Departamento de Microbiología de la Universidad de Talca.

En todos los procedimientos descritos anteriormente el paciente no presentará riesgos ni consecuencias.

Es importante señalar que todos los datos personales obtenidos son confidenciales y la muestra obtenida será utilizada exclusivamente para fines científicos. A su vez destacar que su participación es completamente voluntaria, si no desea ser partícipe del presente proyecto de investigación, su negativa no le traerá ningún inconveniente.

Al respecto, expongo que:

He sido informado/a sobre el estudio a desarrollar y las eventuales molestias, incomodidades y ocasionales riesgos que la realización del procedimiento implica, previamente a su aplicación y con la descripción necesaria para conocerlas en un nivel suficiente.

He sido también informado/a en forma previa a la aplicación, que los procedimientos que se realicen, no implican un costo que yo deba asumir. Mi participación en el procedimiento no involucra un costo económico alguno que yo deba solventar (hacerme cargo).

Junto a ello he recibido una explicación satisfactoria sobre el propósito de la actividad, así como de los beneficios sociales o comunitarios que se espera éstos produzcan.

Estoy en pleno conocimiento que la información obtenida con la actividad en la cual participaré, será absolutamente confidencial, y que no aparecerá mi nombre ni mis datos personales en libros, revistas y otros medios de publicidad derivadas de la investigación ya descrita.

Sé que la decisión de participar en esta investigación, es absolutamente voluntaria. Si no deseo participar en ella o, una vez iniciada la investigación, no deseo proseguir colaborando, puedo hacerlo sin problemas. En ambos casos, se me asegura que mi negativa no implicará ninguna consecuencia negativa para mí.

Adicionalmente, los investigadores responsables TM. Mg. Pedro Brevis A, email: pbrevis@ utalca.cl, fono: (071) 200489, han manifestado su voluntad en orden a aclarar cualquier duda que me surja sobre mi participación en la actividad realizada. Para ello, se me informa que el domicilio para estos efectos es Campus Lircay s/n, (071) 200489, en el horario comprendido entre las 8:30-18: 30, en el período comprendido en la investigación y hasta 6 meses después de concluida ésta. 
También puedo contactarme con el Comité de Bioética, a través de la Dirección de Investigación de la Universidad de Talca (Sr. Daniel Vivanco, email dvivanco@utalca.cl, Teléfono 71-200484 o Srta. Sandra Cofré, email scofre@utalca.cl, Teléfono 71-200825.

He leído el documento, entiendo las declaraciones contenidas en él y la necesidad de hacer constar mi consentimiento, para lo cual lo firmo libre y voluntariamente, recibiendo en el acto copia de este documento ya firmado.

Yo, Cédula de identidad o pasaporte $\mathrm{N}^{\circ}$ de nacionalidad mayor de edad o autorizado por mi representante legal, con domicilio en

par en la investigación denominada: "Aislamiento e identificación de Malassezia spp. en pacientes con Pitiriasis versicolor y Dermatitis seborreica en la ciudad de Talca" y autorizo al señor TM. Mg. Pedro Brevis A., investigador responsable del proyecto y/o a quienes éste designe como sus colaboradores directos y cuya identidad consta al pie del presente documento, para realizar el (los) procedimiento (s) requerido (s) por el proyecto de investigación descrito.

Fecha:

Hora:

Firma de la persona que consiente: 